\title{
Multicystic meningioangiomatosis
}

\author{
Peifeng $\mathrm{Li}^{1,2+}$, Guangbin $\mathrm{Cui}^{3+}$, Yingmei Wang ${ }^{2}$, Ming Geng ${ }^{1 *}$ and Zhe Wang ${ }^{2^{*}}$
}

\begin{abstract}
Background: Meningioangiomatosis (MA) is a rare hamartomatous lesion. Only six cases of cystic MA have been reported in the literature.

Case presentation: We present a case of multicystic MA. A 21-year-old woman without any stigmata of neurofibromatosis type 2 presented with intractable seizures since 10 years. Brain magnetic resonance imaging revealed a well-defined, multicystic mass with heterogeneous signal intensity in the right temporal lobe. The patient underwent resection of the lesion and of the epileptogenic cortex under intraoperative electrocorticography (ECoG) assistance. Histopathological examination showed proliferation of perivascular cells that were arranged in a cuff pattern and were positive for vimentin, D2-40 and smooth muscle actin. Mutiple microcysts and enlarged perivascular spaces were present, which was similar to the structure of the arachnoid cavity. Hyalinized collagen fibers with round concentric acellular eosinophilic lamellae within areas of reactive gliosis were noted for the first time in MA. The patient was followed up without any clinical symptoms or recurrence for 2 years.

Conclusion: MA may originate from arachnoid and vascular tissue trapped in the cortical parenchyma during brain development, and the cysts may have resulted from the gradual accumulation of cerebrospinal fluid in the perivascular spaces of the trapped tissue. Resection of the lesion and of the epileptogenic cortex is important not only for pathological diagnosis but also for seizure control, and intraoperative ECoG assistance is recommended.
\end{abstract}

Keywords: Meningioangiomatosis, Multicystic, Seizure, Hamartomatous lesion

\section{Background}

Meningioangiomatosis (MA) is a rare and benign congenital disorder that involves the cortex and the overlying leptomeninges and primarily affects children and young adults [1]. It may occur sporadically or in association with neurofibromatosis type 2 (NF2) [2]. Approximately 120 cases of MA have been reported in the literature. Of these, only six cases were accompanied by cystic lesions [3-7]. We assess the clinical, eletrophysiological, imaging and pathological features of a case of sporadic MA with multiple microcysts, and herein, we discuss the mechanisms and treatment of this disorder.

\footnotetext{
*Correspondence: gm2227@sina.com; zhwang@fmmu.edu.cn

${ }^{\dagger}$ Equal contributors

'Department of Pathology, General Hospital of Jinan Military Command, Ji'nan 250031, China

${ }^{2}$ Department of Pathology, State Key Laboratory of Cancer Biology, Xijing Hospital and School of Basic Medicine, Fourth Military Medical University, Xi'an 710032, China

Full list of author information is available at the end of the article
}

\section{Case presentation}

A 21-year-old woman presented with a history of intractable focal evolving to bilateral convulsive seizures since the age of 10 years and complained of an increase in the frequency of the seizures in the last 5 months. Eleven years ago, she experienced a complicated febrile seizure with left limb convulsion and unconsciousness, which continued for $6 \mathrm{~h}$; her mental status fully recovered after $24 \mathrm{~h}$. Thereafter, generalized tonic-clonic seizures occurred almost every month, in spite of medical treatment with carbamazepine, phenobarbital and sodium valproate. She had no history of adverse perinatal events, developmental problems or head trauma. General physical and neurological examinations were unremarkable; she had no stigmata or family history of NF. Inpatient continuous video electroencephalography (EEG) revealed right temporal seizure foci with significant sharp wave activity and spike-and-slow waves complex during drowsiness and sleep. Magnetic resonance imaging (MRI) of the brain demonstrated a multicystic mass with low signal intensity on T1-weighted images and high signal intensity on T2-weighted images in the right temporal lobe 
(Figure 1). The cysts were isointense with the cerebrospinal fluid (CSF) on T1- and T2-weighted MRI. On fluid-attenuated inversion-recovery sequence, the lesion appeared as heterogeneous hypointense mass. The lesion was well-demarcated without any perifocal edema. Clinically, a dysembryoplastic lesion was suspected. The patient underwent right temporal craniotomy and lesionectomy. Before resection, an intraoperative electrocorticography (ECoG) was performed over the lesion. The ECoG showed that epileptic foci were located in the right superior temporal gyrus, the upper part of the middle temporal gyrus and the right hippocampus. These lesions were resected under a surgical microscope. The patient was discharged 13 days after the procedure without any neurological complications. She received postoperative treatment with antiepileptic drugs for 10 months. Her postsurgical course was uneventful, and a 2-year follow-up did not reveal any recurrence of the lesion.

Gross examination of the resected right temporal lobe revealed some whitish tissue that measured $5.0 \mathrm{~cm} \times$ $2.5 \mathrm{~cm} \times 1.5 \mathrm{~cm}$ and had medium consistency and multiple, small, fluid-filled cysts. The right hippocampus showed some whitish tissue measuring $0.8 \mathrm{~cm} \times 0.5 \mathrm{~cm} \times 0.5 \mathrm{~cm}$.

On microscopic examination, the lesion was observed to be located within the cortex and the underlying white matter, with focal involvement of the overlying leptomeninx. Pathological examination showed unique features of MA, including prominent proliferation of both the small vessels (mainly capillaries and venules) and perivascular cells, which resembled meningothelial or fibroblast cells, arranged in whorls and cuffs (Figure 2A). Microcystic components and enlarged perivascular spaces were observed within or around the perivascular cell cuffs, and some of these cysts were similar to the arachnoid cavity (Figure 2B). The perivascular cells showed direct transition into the microcystic areas or enlarged spaces, which had variable diameters and were lined with a single layer of spindle cells, but the microcysts were not connected with the vessels directly. Cord-like nests of hyperplastic fibroblast-like cells were found perpendicular to the surface of the cerebral cortex, where encephalocele and leptomeningeal cell proliferation were present. Many round eosinophilic nodules with a concentric arrangement of acellular lamellae within reactive gliosis were seen between the foci of perivascular cuffs; these nodules may have represented hyalinized collagen fibers (Figure 2C). This might have been a reactive phenomenon rather than an intrinsic MA component. Mitotic activity, cellular atypia and necrosis were not identified. In the right hippocampus, neuronal degeneration and gliosis were observed.

To determine the origin of the proliferative or lesional cells, immunohistochemical examination was performed using the Ventana BenchMark XT system (Roche Ltd., Ohio, USA). Antibodies against the following antigens were used: vimentin (clone V9; Maixin, Fuzhou, China), smooth muscle actin (SMA, clone 1A4; Dako, Carpinteria, CA, USA), epithelial membrane antigen (EMA, clone E29; Maixin), cytokeratin (CK, clone AE1/AE3; Maixin), D2-40 (clone D2-40, Dako), factor VIII (Maixin), CD31 (clone JC70A, Dako), CD34 (clone QBEnd/10; Zhongshan, Peking, China), H-cald (clone H-cald, Dako), glial fibrillary acidic protein (GFAP, clone GA-5; Maixin), neurofilament (clone 2F11, Dako) and Ki-67 protein (clone MIB-1, Dako). The perivascular cells were mainly immunopositive for vimentin and D2-40, focally or weakly positive for SMA, EMA and CD34, and negative for CK, CD31, $\mathrm{H}$-cald, GFAP and neurofilament (Figure 2D,E and F). The cyst walls were often immunoreactive for vimentin,

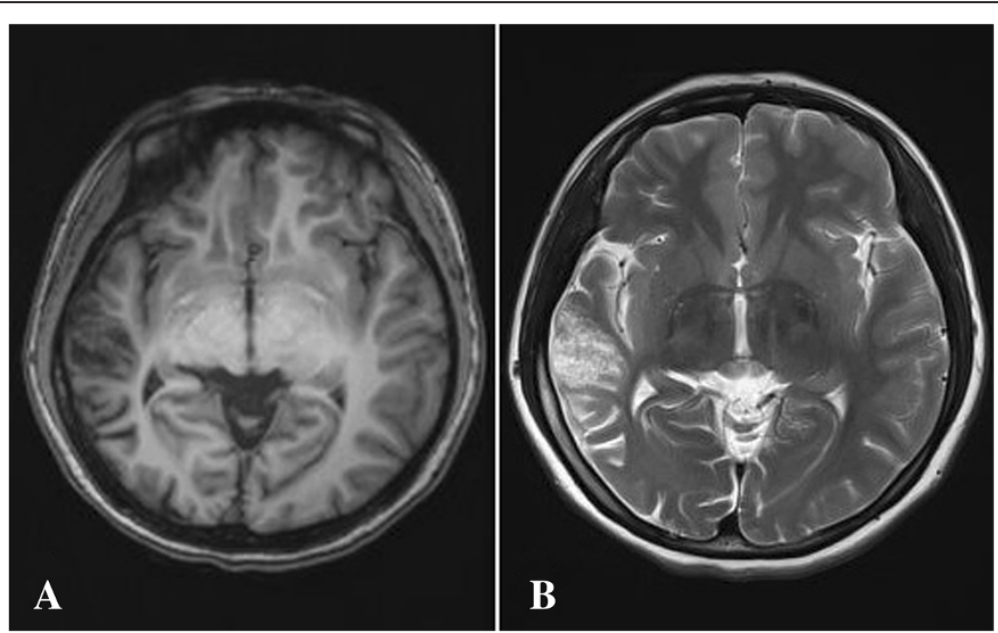

Figure 1 Axial brain magnetic resonance imaging (MRI) findings. A multicystic mass (arrow) with low signal intensity on T1-weighted images (A) and high signal intensity on T2-weighted images (B) is seen in the right temporal lobe. The cystic component was isointense with the cerebrospinal fluid on all sequences. 


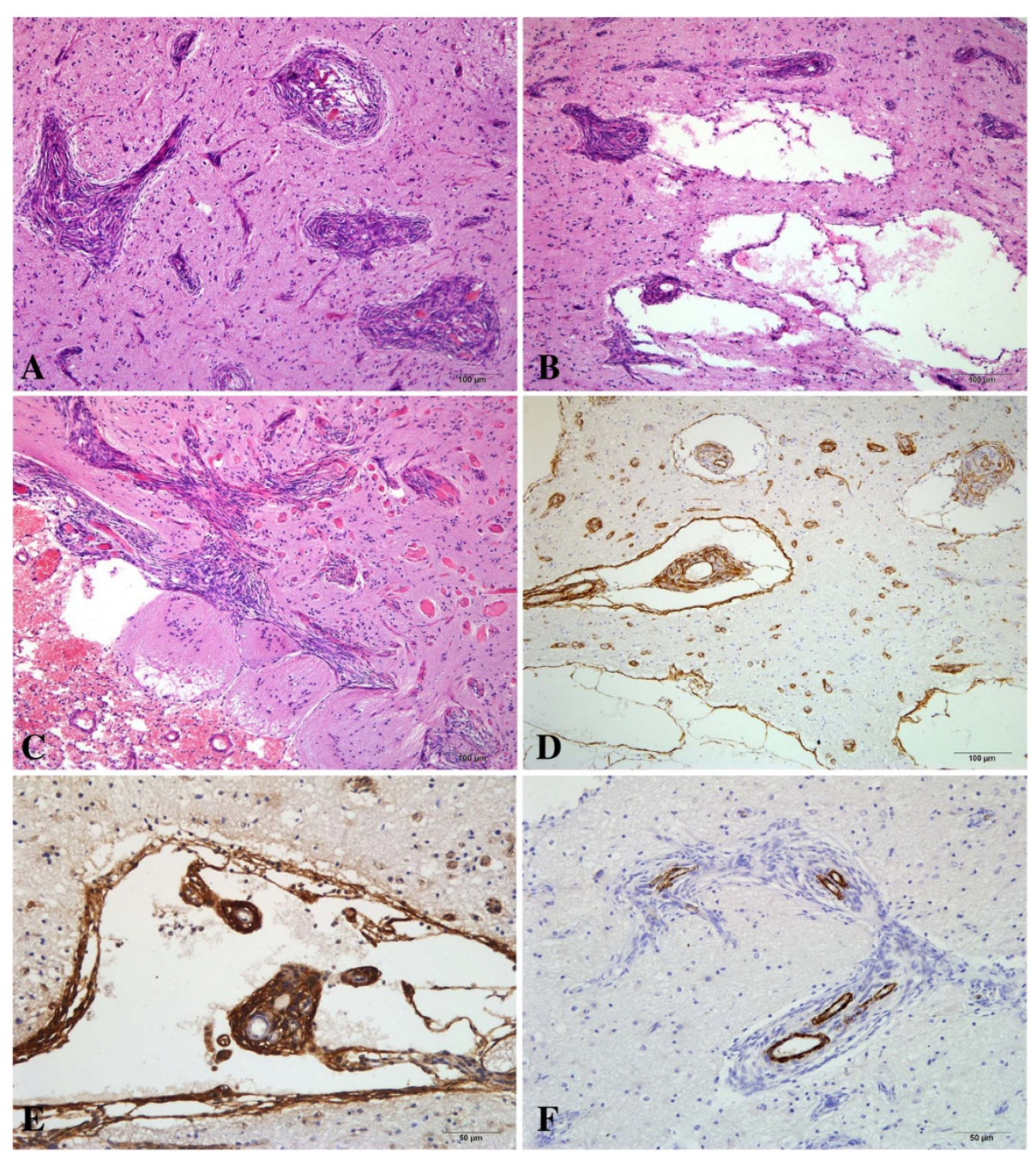

Figure 2 Pathological findings of meningioangiomatosis (MA). (A) The cortical component of the lesion shows prominent small blood vessels surrounded by perivascular meningothelial cell proliferation, which is the characteristic morphology of MA (hematoxylin-eosin, HE; $\times 100$ ). (B) Dilated perivascular spaces and cysts are present within the perivascular cell cuffs ( $\mathrm{HE}, \times 100)$. (C) Cord-like nests of hyperplastic spindle cells are seen perpendicular to the surface of the cerebral cortex, where encephalocele and leptomeningeal cell proliferation are present. Hyalinized collagen fibers appear as concentrically arranged acellular eosinophilic lamellae within areas of reactive gliosis (HE, $\times 100)$. (D) The perivascular cells and cystic walls are focally positive for smooth muscle actin (immunohistochemistry, IHC; $\times 100$ ). (E) The perivascular cells and cystic walls are positive for D2-40 (IHC, ×200). (F) The perivascular cells are negative for $\mathrm{H}$-cald $(\mathrm{IHC}, \times 200)$.

D2-40 and SMA, and less frequently for CK, H-cald and CD34. Immunoreactions with CD34, CD31 and factor VIII were detected within the cytoplasm and/or the plasmalemma of the vessels in the center of the perivascular cuffs. Ki-67 staining revealed no immunoreactive nuclei in the perivascular cells. The cerebral cortex between the perivascular cell nests was immunopositive for GFAP, neurofilament and EMA. The final diagnosis was multicystic MA.

\section{Discussion}

MA is a rare and benign meningovascular hamartomatous condition that usually involves the cerebral cortex in the frontal or temporal regions, with varying involvement of the overlying leptomeninges. The lesions are often associated with NF2, although the majority of cases are sporadic [8]. Sporadic MA usually occurs as a solitary lesion in young patients and presents with a history of intractable seizures or persistent headaches $[9,10]$. In contrast, NF2associated MA more frequently involves multiple lesions and is asymptomatic [11]. In some patients, MA may be accompanied by tumors such as meningiomas, astrocytomas and oligodendroglioma [12-14].

All MA lesions share common pathological features, namely, cortical vascular proliferation and perivascular cuffs of proliferative, spindle-shaped, meningothelial-like cells. Although approximately 120 cases of MA have been reported to date worldwide, only six cases of cysts within 
Table 1 Summary of seven cases of cystic meningioangiomatosis

\begin{tabular}{|c|c|c|c|c|c|c|}
\hline Authors & $\begin{array}{l}\text { Age } \\
\text { (yrs)/sex }\end{array}$ & Symptoms and signs & Radiological findings & Cyst characteristics & Operation & Postoperative outcome \\
\hline Fedi M [3] & $18 / F$ & $\begin{array}{l}\text { Rapidly progressing right } \\
\text { hemiparesis and urinary } \\
\text { incontinence }\end{array}$ & $\begin{array}{l}\text { Three lesions in the left frontal cortex and } \\
\text { subcortical white matter, a large meningioma } \\
\text { in the foramen magnum, bilateral acoustic } \\
\text { and right trigeminal neuromas }\end{array}$ & Small cysts within the lesions & Resection of meningioma & $\begin{array}{l}\text { Died of bilateral brainstem } \\
\text { infarction } 8 \text { months later }\end{array}$ \\
\hline Wang Y [4] & $12 / \mathrm{M}$ & $\begin{array}{l}\text { Intractable seizures for } \\
7 \text { years }\end{array}$ & Cystic lesion in the left frontal lobe & Large cyst within the lesion & Lesionectomy & $\begin{array}{l}\text { Seizures controlled with } \\
\text { antiepileptic drugs for } 10 \text { months }\end{array}$ \\
\hline $\begin{array}{l}\text { Kobayashi } \\
\mathrm{H}[5]\end{array}$ & $14 / \mathrm{M}$ & $\begin{array}{l}\text { Intractable seizures for } \\
3 \text { years }\end{array}$ & $\begin{array}{l}\text { A } 2-3 \mathrm{~cm} \text { mass containing small cysts in the } \\
\text { left frontal lobe; the mass was hypointense } \\
\text { on } T 1 \text { images and isointense on } \mathrm{T} 2 \text { images }\end{array}$ & $\begin{array}{l}\text { Small cysts in the } \\
\text { periphery of the lesion }\end{array}$ & Total removal & $\begin{array}{l}\text { Seizures controlled with two } \\
\text { antiepileptic drugs for } 10 \text { months }\end{array}$ \\
\hline $\begin{array}{l}\text { Kuchelmeister } \\
\text { K [6] }\end{array}$ & $58 / \mathrm{M}$ & $\begin{array}{l}\text { Headache, forgetfulness } \\
\text { for } 10 \text { years }\end{array}$ & $\begin{array}{l}\text { Multiple cysts and a meningioma in the } \\
\text { right frontal lobe }\end{array}$ & Septated large multiple cysts & Total removal & $\begin{array}{l}\text { Forgetfulness persisted; no } \\
\text { recurrence of the lesion for } \\
2 \text { years after the surgery }\end{array}$ \\
\hline \multirow[t]{2}{*}{ Park MS [7] } & $47 / F$ & $\begin{array}{l}\text { Headache, generalized } \\
\text { seizures for } 5 \text { years }\end{array}$ & $\begin{array}{l}\text { Round calcified masses and eccentric cysts } \\
\text { with edema in the left frontoparietal and } \\
\text { right parietal lobes }\end{array}$ & Eccentric cysts in the left lesion & $\begin{array}{l}\text { Total removal of the } \\
\text { left lesion }\end{array}$ & $\begin{array}{l}\text { No seizures or headaches for } \\
15 \text { months after the surgery }\end{array}$ \\
\hline & $53 / \mathrm{M}$ & $\begin{array}{l}\text { Headache, generalized } \\
\text { seizures for } 2 \text { years }\end{array}$ & $\begin{array}{l}\text { Dense round calcified cysts in the left frontal } \\
\text { and parietal lobes }\end{array}$ & $\begin{array}{l}\text { Multiple macrocysts within } \\
\text { the lesions }\end{array}$ & $\begin{array}{l}\text { Total removal of both frontal } \\
\text { and parietal lesions }\end{array}$ & $\begin{array}{l}\text { No seizures or headaches for } \\
7 \text { months after the surgery }\end{array}$ \\
\hline Author's case & $21 / F$ & $\begin{array}{l}\text { Generalized complex } \\
\text { seizures for } 11 \text { years }\end{array}$ & $\begin{array}{l}\text { Lesion showing heterogeneous signals in } \\
\text { the right temporal lobe }\end{array}$ & Multiple microcysts within the lesion & Total surgical removal & $\begin{array}{l}\text { No seizures for } 2 \text { years after } \\
\text { the surgery }\end{array}$ \\
\hline
\end{tabular}


the MA lesion have been described in the literature (Table 1) [3-7]. The mean age of these seven patients with cystic MA including our patient was 32 years (range, 12-58 years). Except for one patient for whom insufficient data were available, all patients had intractable seizures or headaches for 2-11 years (mean, 6 years). In two patients, the cysts were visible only on microscopic examination (microcysts); in three patients, the cysts were sufficiently large to be detected on MRI. The diagnosis of MA was confirmed by the pathologist in all seven patients. Wiebe et al. described the histopathological spectrum of MA, which can be broadly classified into predominantly cellular and predominantly vascular types [8]. In our case, the MRI finding of a multicystic structure differentiated the condition from ordinary MA. According to the literature $[1,3,6]$, patients with cystic MA are older than patients with non-cystic MA, and the interval between symptom onset and surgery is longer in the former. We therefore consider that cystic/microcystic MA should be classified as a new type of MA in order to better our understanding of this disease and achieve an accurate preoperative diagnosis.

The mechanisms involved in the development of MA have not yet been elucidated. MA was considered a hamartomatous proliferation of meningothelial cells, blood vessels and fibroblasts in variable proportions [4]. However, the observation of abnormal local vascularization in some patients has led several authors to regard MA simply as a vascular malformation with an added meningothelial reaction [15]. Furthermore, it has also been suggested that these tumors do not grow or display malignant features. Some studies have supported the opinion that MA may be related to NF2 gene mutation because of its concomitance with NF2 [16]. In our patient, immunohistochemical examination demonstrated that the perivascular cells had originated from arachnoid cap cells. Considering the histopathological findings, the patient's age at onset and the location of the lesion, we propose that MA is a hamartoma that results from the trapping of arachnoid and vascular tissue in the cerebral parenchyma during brain development, rather than a true neoplasm. The wide spectrum of immunohistochemical staining patterns observed in the perivascular cells in MA lesions in the cases reported in the literature and in our case suggests that MA originates from pluripotent cells. The exact mechanism underlying cyst development in MA remains controversial. It has been speculated that cysts form due to the accumulation of CSF within the lesion in a manner similar to the mechanism of cyst formation in cystic meningiomas [7]; however, a communication between the cysts and the subarachnoid space has not been confirmed in MA [5]. In our patient, the proliferation of meningothelial-like cells and loose perivascular cells observed on the cortical surface may have been the early stages of the typical cystic lesion in the deep cortex and white matter, and the cystic component was attributable to the enlarged perivascular spaces. The long duration of the illness supports this hypothesis. The fact that the cysts were not connected with the vessels and that the cyst contents were similar to those of the arachnoid cavity demonstrated that the cysts had originated from arachnoid tissue. Furthermore, the same immunoresponse of the perivascular cells, microcystic walls and the arachnoid cavity wall suggests that pluripotent cells differentiate into the various cell types found in MA [17] and that the formation of cysts is an accompanying developmental anomaly. Mechanisms such as increased CSF pulsation, vascular ectasia, small blood vessel obstruction or abnormal arterial wall permeability may be related to the formation of enlarged perivascular spaces, in which CSF gradually accumulates, eventually resulting in the formation of microcysts and cysts. This suggests that MA originates from pluripotent arachnoidal cap cells trapped in the cerebral cortex.

Although many cases of MA have been described, presurgical diagnosis remains difficult because the wide spectrum of clinical, imaging and electrophysiological features often impedes the clinical diagnosis $[13,18,19]$. Surgical resection is important not only for seizure control but also for pathological diagnosis. Wiebe et al. reported that after surgical removal of the tumor, long-term seizures disappeared in $43 \%$ of patients, improvement occurred in $30 \%$ of patients and antiepileptic drug administration was required in more than $70 \%$ of patients [8]. Partial removal of the tumor has been shown to improve symptoms, but total removal still seems to be more effective $[8,20]$. In patients in whom postoperative seizure control was not successful, extension of the epileptic foci was found to occur with time [21]. In our patient, ECoG revealed perilesional cortical spikes, and epileptogenic foci were present in not only the right temporal lobe but also the right hippocampus. Therefore, intraoperative or extraoperative ECoG is essential for detecting epileptogenic foci [22], which often exist in the adjacent cortex rather than in the lesion. In the present case, total surgical removal was achieved using intraoperative ECoG assistance, and a favorable outcome was obtained.

\section{Conclusion}

The present case demonstrates that MA may present as a hamartomatous lesion containing multiple microcysts in a patient with medically refractory seizures, and should be considered in the differential diagnosis of intracortical lesions, especially in young adults. It is possible that MA originates from arachnoid and vascular tissue trapped in the cortical parenchyma during brain development, and that the cysts result from gradual accumulation of CSF in the perivascular spaces that develop from the trapped tissue. Our data do not support a meningeal origin of MA, 
but rather suggest that pluripotent arachnoid cap cells differentiate into the various cell types found in MA. Resection of the lesion and of the epileptogenic cortex is important not only for pathological diagnosis but also for seizure control, and intraoperative ECoG assistance is recommended.

\section{Consent}

Written informed consent was obtained from the patient for publication of this case report and any accompanying images. A copy of the written consent is available for review by the Editor of this journal.

\section{Abbreviations}

MA: Meningioangiomatosis; ECoG: Electrocorticography; NF: Neurofibromatosis; EEG: Electroencephalography; MRI: Magnetic resonance imaging; CSF: Cerebrospinal fluid; SMA: Smooth muscle actin; EMA: Epithelial membrane antigen; GFAP: Glial fibrillary acidic protein; HE: Hematoxylin-eosin.

\section{Competing interests}

The authors declare that they have no competing of interests.

\section{Authors' contributions}

Acquisition of data: PL, MG and ZW. Analysis and interpretation of data: YW and GC. Drafting of the manuscript: PL, GC and YW. Critical revision of the manuscript for important intellectual content: MG and ZW. All authors read and approved the final manuscript.

\section{Acknowledgements}

This work was funded by the National Natural Science Foundation of China (No. 81272651, to ZW). Additional funding was provided by the President Fund of the General Hospital of Jinan Military Command(to MG). The authors wish to acknowledge the professional English editing service of Elixigen Co (Huntington Beach, CA).

\section{Author details}

'Department of Pathology, General Hospital of Jinan Military Command, Ji'nan 250031, China. ${ }^{2}$ Department of Pathology, State Key Laboratory of Cancer Biology, Xijing Hospital and School of Basic Medicine, Fourth Military Medical University, Xi'an 710032, China. ${ }^{3}$ Department of Radiology, Tangdu Hospital, Fourth Military Medical University, Xi'an 710038, China.

Received: 5 January 2014 Accepted: 13 February 2014 Published: 20 February 2014

\section{References}

1. Jamil O, Ramkissoon S, Folkerth R, Smith E: Multifocal meningioangiomatosis in a 3-year-old patient. J Neurosurg Pediatr 2012, 10:486-489.

2. Ostenfeld EB, Erichsen R, Thorlacius-Ussing $\mathrm{O}$, Riis AH, Sorensen $H T$ : Use of systemic glucocorticoids and the risk of colorectal cancer. Aliment Pharmacol Ther 2013, 37:146-152.

3. Fedi M, Kalnins RM, Shuey N, Fitt GJ, Newton M, Mitchell LA: Cystic meningioangiomatosis in neurofibromatosis type 2: an MRI-pathological study. Br J Radiol 2009, 82:e129-e132.

4. Wang Y, Gao X, Yao ZW, Chen H, Zhu JJ, Wang SX, Gao MS, Zhou LF, Zhang FL: Histopathological study of five cases with sporadic meningioangiomatosis. Neuropathology 2006, 26:249-256.

5. Kobayashi H, Ishii N, Murata J, Saito H, Kubota KC, Nagashima K, Iwasaki Y: Cystic meningioangiomatosis. Pediatr Neurosurg 2006, 42:320-324.

6. Kuchelmeister K, Richter HP, Kepes JJ, Schachenmayr W: Case report: microcystic meningioma in a 58-year-old man with multicystic meningioangiomatosis. Neuropathol Appl Neurobiol 2003, 29:170-174.

7. Park MS, Suh DC, Choi WS, Lee SY, Kang GH: Multifocal meningioangiomatosis: a report of two cases. AJNR Am J Neuroradiol 1999, 20:677-680.
8. Wiebe S, Munoz DG, Smith S, Lee DH: Meningioangiomatosis. A comprehensive analysis of clinical and laboratory features. Brain 1999, 122(Pt 4):709-726.

9. Feng $\mathrm{R}, \mathrm{Hu}$ J, Che X, Pan L, Wang Z, Zhang M, Huang F, Xu B, Mao R, Sun A, et al: Diagnosis and surgical treatment of sporadic meningioangiomatosis. Clin Neurol Neurosurg 2013, 115:1407-1414.

10. Batra A, Prayson RA: Meningioangiomatosis associated with focal cortical dysplasia and neurofibrillary tangles. Clin Neuropathol 2013, 32:37-41.

11. Omeis I, Hillard VH, Braun A, Benzil DL, Murali R, Harter DH: Meningioangiomatosis associated with neurofibromatosis: report of 2 cases in a single family and review of the literature. Surg Neurol 2006, 65:595-603.

12. Lopez Jl, Ereno C, Oleaga L, Areitio E: Meningioangiomatosis and oligodendroglioma in a 15-year-old boy. Arch Pathol Lab Med 1996, 120:587-590.

13. Cui H, Shi H, Chen X, Wang W, Lai R, Han A: Clinicopathological features of meningioangiomatosis associated with meningioma: a case report with literature review. Case Rep Oncol Med 2012, 2012:296286.

14. Prayson RA, Fong J, Najm I: Coexistent pathology in chronic epilepsy patients with neoplasms. Mod Pathol 2010, 23:1097-1103.

15. Blumenthal D, Berho M, Bloomfield S, Schochet SS Jr, Kaufman HH: Childhood meningioma associated with meningio-angiomatosis. Case report. J Neurosurg 1993, 78:287-289.

16. Kim NR, Cho SJ, Suh YL: Allelic loss on chromosomes 1p32, 9p21, 13q14, $16 q 22,17 p$, and $22 q 12$ in meningiomas associated with meningioangiomatosis and pure meningioangiomatosis. J Neurooncol 2009, 94:425-430.

17. Koutsopoulos AV, Yannopoulos A, Stathopoulos EN, Evangeliou A, Panayiotides JG, Kafousi M, Krasoudakis A, Markakis E, Delides GS: Meningioangiomatosis with predominantly cellular pattern. Neuropathology 2003, 23:141-145.

18. Barbosa-Silva E, Dellaretti M, de Carvalho GT, Pereira JL, Botrel L Jr, Pittella JE, de Sousa AA: Meningioangiomatosis without neurofibromatosis simulating encephalitis in neuroimaging. Surg Neurol Int 2012, 3:34.

19. Kashlan ON, Laborde DV, Davison L, Saindane AM, Brat D, Hudgins PA, Gross RE: Meningioangiomatosis: a case report and literature review emphasizing diverse appearance on different imaging modalities. Case Report Neurol Med 2011, 2011:361203.

20. Jallo Gl, Kothbauer K, Mehta V, Abbott R, Epstein F: Meningioangiomatosis without neurofibromatosis: a clinical analysis. J Neurosurg 2005, 103:319-324.

21. Takeshima Y, Amatya VJ, Nakayori F, Nakano T, Sugiyama K, Inai K: Meningioangiomatosis occurring in a young male without neurofibromatosis: with special reference to its histogenesis and loss of heterozygosity in the NF2 gene region. Am J Surg Pathol 2002, 26:125-129.

22. Asano $E$, Brown $E C$, Juhasz $C$ : How to establish causality in epilepsy surgery. Brain Dev 2013, 35:706-720.

doi:10.1186/1471-2377-14-32

Cite this article as: Li et al:: Multicystic meningioangiomatosis. BMC Neurology 2014 14:32

\section{Submit your next manuscript to BioMed Central and take full advantage of:}

- Convenient online submission

- Thorough peer review

- No space constraints or color figure charges

- Immediate publication on acceptance

- Inclusion in PubMed, CAS, Scopus and Google Scholar

- Research which is freely available for redistribution 